\title{
LAS DOTES A MONJAS, BEATAS, ABANDONADAS Y DESCARRIADAS DE LA CASA PÍA DE LA MISERICORDIA DE SEVILLA
}

\author{
Paula Rivasplata \\ Universidad San Ignacio de loyola (Lima, Perú) \\ UNIVERSIDAD DE SEVILLA
}

RESUMEN: El Hospital de la Misericordia era una casa pía ubicada en la ciudad de Sevilla que fue fundada a fines del siglo XV con el objetivo principal de dotar a jóvenes pobres y huérfanas para tomar estado de casada. Este hospital administraba los legados testamentarios dejados bajo su custodia para distribuirlos en diversas obras de caridad y sólo podía entregar dotes para religiosas, abandonadas y descarriadas si tal era el deseo del donante.

PALABRAS CLAVE: monjas, beatas, abandonadas, prostitutas, dote, Misericordia, Sevilla.

\section{THE DOWRIES TO NUNS, PIOUS AND ABANDONED WOMEN AND PROSTITUTES OF THE SEVILLA HOSPITAL}

\begin{abstract}
The Mercy hospital was a pious house located in the city of Seville which was founded in the late fifteenth century with the main objective of providing marriage dowries for poor and orphans. This hospital administered the bequests left in their custody for distribution to various charities and could only deliver dowries to religious women, abandoned ones and prostitutes if that was the wish of the donor.
\end{abstract}

KEYWORDS: nuns, pious women, abandoned women, prostitutes, dowry, Mercy, Seville

Recibido: 02/10/2016/Aceptado: 05/12/2016 
El hospital de la Misericordia de Sevilla fue fundado por Antón Ruiz, clérigo capellán de don Pedro Enríquez, Adelantado Mayor de Andalucía y Señor de Tarifa, junto a otros cofrades en $1476^{1}$. Su objetivo primordial fue dotar para casamiento a doncellas pobres y/o huérfanas desamparadas. Sin embargo, el hospital recibía testamentos en los que constaba la voluntad de cada donador que los administradores debían de cumplir como la entrega de ropas, limosnas, la liberación de cautivos de moros, la realización de fiestas religiosas y la administración de capellanías para la realización de misas de difuntos, entre otros ${ }^{2}$. Se la conocía como hospital, pero no cumplía con esa función, pues era una casa pía que administraba las voluntades testamentarias delegadas a ella. En este marco, el objetivo de este trabajo se centra en conocer a algunas de las destinatarias de las dotes entregadas por el Hospital de la Misericordia, como eran las religiosas, beatas, abandonadas y descarriadas. Grupo minoritario dentro de la población de mujeres dotadas por esta institución religiosa cuyo objetivo principal era dotar para matrimonio a las mujeres pobres sevillanas de buena conducta y fama que hubiesen trabajado como criadas.

Las fuentes consultadas para la realización de este artículo provienen del Archivo Histórico Provincial de Sevilla (AHPS), del Archivo de la Diputación Provincial de Sevilla (ADPS) y del Archivo General de Indias (AGI). Finalizada la fase heurística he dado paso a una hermenéutica en la que se visualiza la activa participación de la casa de la Misericordia de Sevilla en la ayuda a la mujer desamparada de todo estamento social durante el Antiguo Régimen español. En cuanto a la información bibliográfica se debe tener en cuenta que el trabajo presentado es de carácter novedoso y no existe bibliografía puntual sobre el tema investigado en cuanto al tema de dotes a monjas, beatas, abandonadas y descarriadas del Hospital de la Misericordia de Sevilla. Sin embargo se ha recurrido a varios libros en cuanto al tema dote y sobre historia de la institución destaca Alonso Morgado que escribió en 1587, el libro Historia de Sevilla en la cual se contienen sus antigüedades, grandezas y cosas memorables en ella contenidas desde su fundación hasta nuestros tiempos ${ }^{3}$. También ha sido de mucha ayuda la información archivística del fondo documental del Hospital de la Misericordia de Luisa Zahino Peñafort titulada "El Archivo de la Casa de la Misericordia de Sevilla"4.

\footnotetext{
1 ALBARDONEDO, Antonio: "La iglesia nueva del hospital de la Misericordia. Un proyecto de Asensio de Maeda con importantes colaboraciones (1595-1606)", en Laboratorio de Arte, No 16 (2003), p. 69

2 Regla de los hermanos de la Misericordia de la ciudad de Sevilla. Congregación de la Misericordia, Sevilla: Alonso Rodríguez Gamarra, 1622, ff. 52-53 r-v.

${ }^{3}$ MORGADO, Alonso. Historia de Sevilla en la cual se contienen sus antigüedades, grandezas y cosas memorables en ella contenidas desde su fundación hasta nuestros tiempos. Sevilla: Imprenta de Andrea Pescioni y Juan de León, 1587, f. $117 \mathrm{a}$

4 ZAHINO PEÑAFORT, Luisa. "El Archivo de la Casa de la Misericordia de Sevilla", en El Archivo bispalense. Revista bistórica, literaria y artística, Sevilla, 2da época, Tomo LXXV, no 230 (1992), pp. 63-80.
}

Trocadero, $\mathrm{n}^{\circ} 28$ (2016), ISSN 2445-267X, pp. 1-23 
En cuanto al significado de la dote en el Antiguo Régimen servía para sobrellevar la vida matrimonial, amparar a la mujer y alcanzar el estado femenino ideal, el matrimonio, que el Estado a través de las leyes, la Iglesia con su medición, la comunidad, la familia y las mujeres mismas entendían como natural. ${ }^{5}$ Pero, también se necesitaba de una dote para entrar a convento. De esta manera, la dote se convirtió, al menos entre los más ricos y poderosos, en una manera de afirmar su poder frente a la sociedad, de ahí el derroche y lujo, al menos en la Castilla de la segunda mitad del XVI y comienzos del XVII. Indudablemente, entre los pobres, la dote estaba íntimamente relacionada con la palabra "remediar", pues su fin era precisamente conseguir que la mujer se "remedie" que según el Diccionario de Autoridades significa "enmendar alguna cosa" "poner remedio al daño". Casarse era una solución para enmendar la suerte de una mujer por lo que la dote era un señuelo para atraer al pretendiente.

En la legislación, el Código de las Siete Partidas de Alfonso X, "el Sabio" en el siglo XIII introduce la dote del perfil romano, entendiéndola como la donación que hace la mujer al marido para sostener las cargas del matrimonio ${ }^{6}$. A comienzos del siglo XVI, en las Leyes de Toro, se consolida la dote como aportación femenina al matrimonio y se introduce los límites dotales. En cuanto a la Recopilación de Leyes de estos Reinos mandada hacer por Felipe II en 1567, se determinó la cantidad máxima que se le podía entregar a cada hija de acuerdo con los ingresos familiares y que no podría superar el quinto total del patrimonio familiar. Las mencionadas leyes no se cumplieron, por lo que se reiteraron algunas veces, como en la Pragmática de Felipe IV en 1627, que continuaba dando dispensas para que se pudieran superar los límites impuestos a las dotes. Esta época de dotes altísimas -mediados del XV a la primera mitad del XVII- también coincidió que la mayor cantidad de dotes a doncellas pobres canalizadas por la Iglesia a través de obras pías y mandas testamentarias. Igualmente, la dote estaba presente en la Novísima Recopilación de 1805 de las Leyes de España. El Código de 1889 puso fin a la dote legalmente, quedando como costumbre?

En cuanto al contexto histórico o marco social o sociocultural de la institución estudiada se ubica en el Antiguo Régimen en el que las obras pías estaban a cargo de un

\footnotetext{
${ }^{5}$ MARTÍN HERRERA, Lourdes. "Reflexiones sobre la mujer basadas en el estudio de las cartas de dote", en Pilar Ballarín y Teresa Ortiz (eds.). La Mujer en Andalucía. Primer encuentro interdisciplinar de estudios de la mujer. Granada: Universidad de Granada, 1990, t. I, p. 181.

${ }^{6}$ BIRRIEL SALCEDO, Margarita. "Mujeres y matrimonio: Sentido y significación de las arras en la corona de Castilla", en Historia y Género. Imágenes y vivencias de mujeres en España y América (siglos XV-XVIII). Málaga: Universidad de Málaga, 2007, p. 75.

7 PÉREZ-PRENDES y MUÑOZ DE ARRACO, José Manuel. Curso de Historia del Derecho español. Madrid: Editorial Universidad Complutense, 1989.
} 
sector acomodado de la población en forma individual o colectiva (cofradías, hermandades y gremios que practicaban el socorro mutuo), generalmente administrados por la Iglesia $^{8}$. Los núcleos urbanos eran sedes de instituciones y residencias de los grupos rentistas, de modo que allí se concentraban recursos, lugares de acogida y por lo tanto un enorme número de pobres. En la ciudad de Sevilla, el arzobispo, el cabildo catedralicio y algunos eclesiásticos, hidalgos y burgueses perceptores de rentas eran quienes estaban en condiciones de repartir dotes, limosnas o raciones de alimento a través de instituciones religiosas. ${ }^{9}$ Como ya se indicó la principal función del Hospital de la Misericordia era casar doncellas para preservar la honra de las jóvenes pobres, facilitándoles el camino hacia el matrimonio a través de las dotes gratuitas que les regalaban y así remediarlas. El hospital estudiado estaba bien estructurado desde el padre mayor que era la máxima autoridad de la Misericordia que controlaba el cumplimiento de las comisiones asignadas a los hermanos, asistía a las cuentas del mayordomo, repartía las comisiones para las visitas y casamientos de las doncellas. También, formaba parte de la administración el mayordomo, los secretarios de cabildo, de los libros de las doncellas, contadores, letrados, visitadores, escribanos, solicitadores para los pleitos, procuradores y el portero.

\section{LAS DOTES PARA TOMAR ESTADO DE RELIGIOSA}

Este Hospital no podía entregar dotes a mujeres que quisieran entrar a tomar estado de religiosa porque no era el objetivo por el cual fue creado. Aunque los hermanos de la Misericordia consideraran superior el matrimonio espiritual al terrenal, posición que se basaba principalmente en la Biblia y en los textos morales de los Santos Padres que consideraban "el estado de virginidad superior al estado de matrimonio "10 , según el orden establecido por Dios ${ }^{11}$, entendían que:

\footnotetext{
${ }^{8}$ CARASA SOTO, Pedro. El sistema hospitalario español en el siglo XIX. De la asistencia benéfica al modelo sanitaria actual. Valladolid: Universidad de Valladolid/Caja de ahorros y Monte de Piedad de Salamanca, 1985, pp. 3545.

${ }^{9}$ GEREMEK, Bronislaw. La piedad y la horca. Madrid: Alianza Editorial, S.A, 1989, pp. 136-152.

10 GRADI, Basilio: Trattato della verginita et dello stato verginale... In Roma: appresso Bartholomeo Bonfadino, \& Tito Diani, 1584, pp. 37, 38, 41. Basilio Gradi fue un religioso del siglo XVI que defendió el estado virginal, indicando que la virginidad era más difícil de mantener y por eso más meritoria porque voluntariamente se ofrecía. Consideraba que la virginidad era buena y conveniente para la honestidad y libertad del cuerpo y de la mente, útil para la obtención de mercedes que esperan del cielo. Además añadió que sólo por huir de tanta molestia y trabajo que aportaba el matrimonio, era motivo suficiente para que alguno debiese abrazar el celibato y la virginidad. La tentación de la carne se vencía con la fuga y la clausura. Añadió que muchos se habían casado por ignorar los trabajos del matrimonio y desconocer la felicidad y tranquilidad que aportaba el estado virginal.

11 LACARRA, María Eugenia: "Representaciones de mujeres en la literatura española en la Edad Media (escrita en castellano)", en Breve historia feminista de la literatura española (en lengua castellana). II. La mujer en la literatura española. Barcelona: Anthropos, 1993, pp. 21-23.
}

Trocadero, $\mathrm{n}^{\circ} 28$ (2016), ISSN 2445-267X, pp. 1-23 
“...la obligación nuestra es cumplir la voluntad de los testadores como ejecutores perpetuos de ellas solo en caso que el llamamiento fuese hecho a persona señalada por su nombre, podrá esta casa convertir en dicho matrimonio espiritual e ingreso de religión lo que a la tal persona se le hubiese señalado por el testador, pues la manda fue en favor de la tal persona. $\mathrm{Y}$ en este caso no se hace perjuicio a otras, pues no tienen derecho a lo que a esta se la mando especialmente. Y fuera de este caso son perjudicadas las doncellas, que con las dichas dotes que se aplicaron a casamiento espiritual pudieran casar temporalmente en cumplimiento de las voluntades de los testadores".

Así y todo, la Casa Pía de la Misericordia de Sevilla cumplió las voluntades testamentarias que tenían el fin de dotar jóvenes para ingresar a la vida religiosa. Entre ellas destacaron las monjas que ayudaban a otras monjas económicamente. Por ejemplo, en 1626, la monja Luisa de Abrego del convento del Dulce Nombre de Jesús de Sevilla, institución conocida como "las Recogidas" en la collación de San Vicente, pidió a través de Diego de Quintana el pago de 100 ducados de plata que le había dejado como voluntad testamentaria doña Francisca Coronado, monja del monasterio de Nuestra Señora de Belén de Sevilla, lo que el hospital cumplió pero no en plata. ${ }^{12}$ Asimismo, otros donadores legaban rentas para entregar limosnas a modo de ropa a monjas y laicas pobres como la dotación de Antúnez de Valdujo que destinó 300 reales para la compra de sayas y mantos a monjas del convento de Santa Ana, ropa a mujeres laicas y a ocho niños pobres de la collación de San Lorenzo. ${ }^{13}$

Otra costumbre practicada entre los donadores era legar dinero a autoridades para que eligieran a jóvenes merecedoras de una dote de religiosa. Así, en 1550, Pedro de Arbreto recibió de Diego de Carote, contador de la Casa de la Contratación de las Indias, 2000 ducados por mano de Domingo de Lizárraga, para dotar a dos hermanas, Lucia de Mendieta, próxima a profesar en religión, y a Elvira Ortiz de Mendieta, que tenía concertado el matrimonio con Antonio de Arbreto. ${ }^{14}$ Asimismo, una voluntad testamentaria otorgaba al guardián del convento de Nuestra Señora de Loreto la potestad de nombrar a doncellas de dote. En 1635 nombró a diecisiete. ${ }^{15}$

\footnotetext{
12 AHPS, Libro capitular 4744 (1626-1630), 7 de marzo de 1626 Petición de Diego de Quintana.

13 AHPS, Libro capitular 4762 (1741-1746) 06/10/1742; AHPS, Libro cabildo 4766 (1756-1761) 03/02/1761, f. 8 r; AHPS, Libro capitular de acuerdos y cabildos y juntas que se hacen en la Misericordia 4770(1786-1797) 20/10/1790, f.146r-f.149v

${ }^{14}$ Colección de documentos inéditos para la historia de Hispano América, tomo X. Catálogo de los fondos americanos del Archivo de Protocolos de Sevilla, Tomo I, siglo XVI (CON II Apéndices documentales), 1997, p.1664: Libro del año 1550. Oficio X. Libro III. Escribanía Melchor de Fortes, ff. 653. Fecha 13 de noviembre.

15 AHPS, Libro cabildo 4746 (1633-1636), 7/01/1635, f. 220v.
} 
Muchas veces las mismas jóvenes, generalmente pobres, lo solicitaban sin representación alguna, seguramente orientadas por algún miembro que perteneciera a la Misericordia. Así, en 1668, una doncella llamada María, hija de Juan Francisco de Arauz y de doña Rufina de Escobar, pidió ayuda para entrar en religión por ser muy pobre y andar juntando limosna para pagar su dote en el convento de la Victoria de Triana donde iba a profesar. El cabildo acordó que se le diese una dotación de don Fernando Salas de Silveira. ${ }^{16}$ Algunos legados testamentarios daban libertad a la Misericordia para que usaran sus rentas en la manera que consideraran conveniente.

Las dotes más comunes que administraba la Misericordia eran las destinadas a parientes. Así, en 1608 se dio el caso de una monja llamada María de Ordaz que había sido dotada de los bienes y hacienda de Francisco de Ordaz. Le correspondían los gastos de entrada al monasterio que ella quisiese. El monasterio elegido debía realizar una carta de pago. La joven llevaría la fe del auto y el memorial con los objetos entregados que incluían ajuar de ropas de vestir, cama y otras cosas para su entrada en religión al menos eso era así en $1608 .^{17}$

"Petición de María de Ordaz, doncella. Llevó fe de este auto y la memoria original. Esta comisión se vio una petición de María de Ordaz doncella que quiere ser monja en el monasterio de Sevilla de esta ciudad y un memorial que ordenaron los Sres. Licenciado Francisco de Sama y Agustín Quijada, clérigos hermanos de esta casa, de las ropas de vestir y cama y otras cosas que se le han de dar para su entrada en la religión a quienes se cometió este negocio por el cabildo de esta casa de siete de mayo de 1606 que está firmado de sus nombres y acordaron que el Sr. mayordomo Sebastián de Vivar haga las ropas contenidas en el dicho memorial por cuenta de los bienes y hacienda de Francisco de Ordaz difunto que dejó por su heredero al hospital con cargo de dar a la dicha María de Ordaz el dote que le mandó para entrar monja en el monasterio que ella eligiese y los gastos de su entrada y tenga cuenta e razón ... de lo que en ello gastare y ... de todo ello tome carta de pago con los cuales recaudos.

Dotes transatlánticas también fueron enviadas a la Misericordia para que canalizara y cumpliera la voluntad de los testadores. Así, algunos españoles legaban bienes a obras pías desde las Indias. Una de estas dotes registradas en la Misericordia fue la de Francisco de Mostrenco que murió en las Indias en 1561 y dejó dinero a la casa de la Misericordia y a la Capilla de las Doncellas de catedral hispalense. Se realizó un concierto o ajuste entre las instituciones para recibir cada una la mitad de los mil ducados legados

\footnotetext{
${ }^{16}$ AHPS, Libro cabildo 4752,11/11/1668, f. 107v. La petición de María, hija de Juan Francisco de Arauz y de doña Rufina de Escobar en que pide se le dé una dote de la dotación de don Fernando Salas de Silveira para ayuda a su estado de religiosa por ser muy pobre y andar juntando limosna para pagar su dote en el convento de la Victoria de Triana donde está próxima a profesar y se acordó que se le dé uno de la dicha dotación de don Fernando Salas de Silveira.

17 AHPS, Libro cabildo 4742, 1608
}

Trocadero, no 28 (2016), ISSN 2445-267X, pp. 1-23 
porque cada uno alegaba que tal cantidad por completo le pertenecía. ${ }^{18}$ En el siglo XVII fueron más frecuentes los envíos de dinero por testamento, principalmente provenientes del Virreinato Peruano. En 1658, un vecino de Potosí de los reinos del Perú, Francisco de Santa Cruz, nombró por patrono perpetuo del patronato que dejó fundado al cabildo del hospital de la Misericordia. ${ }^{19}$ No sólo se enviaban dotaciones de Ultramar sino que algunas parientas en Indias solicitaban sus dotes al hospital de la Misericordia de Sevilla. En 1686, dos parientas en Lima de Sebastián Zurita pedían sus dotes, una para monja y otra viuda. Recurrieron a un contacto en Sevilla para que les hiciera el trámite ante la Misericordia. La susodicha fue doña Beatriz María de Cuadro, vecina de Sevilla, quien en nombre de doña Ventura de Cuba y Arce, viuda del Sr. don Álvaro Miguel de Vallejo, vecino de la ciudad de los Reyes del Perú, y en nombre de doña Beatriz de Cuba y Arce, monja profesa en el Monasterio de Santa Catalina de Siena de Lima, quienes indicaban que eran parientas de Sebastián de Zurita, de cuya dotación les tocaba 450 ducados y pedía se les pagara. El cabildo acordó de conformidad remitir la solicitud al Sr. don Juan de Molina, el letrado de la institución. ${ }^{20}$ En 1698, otro fue el intermediario en Sevilla para abogar por la dote de religiosa de Sebastián de Zurita. Agustín de Balderrama solicitó en nombre de sor Ana de San Joseph, religiosa profesa en el convento de Santa Catalina de Sena en la ciudad de los Reyes del Perú que se le pagara la dote de la dotación de Sebastián de Zurita en que fue nombrada por don Agustín de Lara, patrono del patronato como parienta del fundador. Habiéndose visto el informe y parecer del Sr. don Julián de Molina y la fundación se acordó de conformidad pagar a la susodicha la dote, la cual se le señalaba en la renta de aquel año. La doncella nombrada era sobrina del veinticuatro Sebastián de Zurita. ${ }^{21}$ Asimismo, en 1699, el cabildo destinó 450 ducados de dote a una religiosa que profesaba en el convento de Santa Catalina de los Reyes del Perú, nombrada en una dote como parienta del capitán Sebastián de Zurita. ${ }^{22}$ Como se observa, el hospital de la Misericordia de Sevilla cumplía con voluntades transatlánticas. Otros legados importantes para dotar a doncellas provenientes de Indias son los de Antonio Pérez Enríquez del virreinato del Perú,

\footnotetext{
18 AHPS, Libro cabildo 4737, Libro cabildo 1552-1561, 08/06/1561, f. 350v. En este cabildo se vido un concierto que Hernando de Deza y el licenciado Alonso Ruíz en nombre de la capilla de las doncellas de la iglesia mayor de esta ciudad y Juan Gutiérrez Pacheco en nombre de este hospital hicieron para que mil ducados que Francisco Mostrenco (legó).

${ }_{19}$ AHPS, Libro cabildo 4751, 14/07/1658, f.119v

20 AHPS, Libro cabildo 4753, 01/12/1686, f.130v.

21 AHPS, Libro cabildo 4754, 06/12/1698, ff. 329r-330r.

22 AHPS, Libro cabildo 4754, 04/07/1699, f. 360v
} 
Francisco de Alba en Cartagena de Indias, Diego de Azúa y Juan Sánchez de Lefa en el Virreinato de Nueva España, entre otros. ${ }^{23}$

La Misericordia podía entregar varias dotes destinadas a parientes a una misma doncella. Fue el caso de doña Antonia de Armizo quien recibiría un tributo de 500 ducados de su tío, el racionero Bartolomé Ruiz y otra dote del clérigo Juan Tenorio, que dejó su hacienda en el hospital para casar a sus parientas. Su padre Juan de Armizo exigió que le entregaran las dotes para que su hija pudiese profesar en el convento de Santa Isabel de Sevilla en 1608. Dos dotes fueron entregadas de dos dotaciones diferentes a la heredera. ${ }^{24}$ En este caso, la joven recibió una escritura de tributo de dinero que era pagado por el usufructo de un bien inmueble. Este documento fue entregado al convento previa carta dotal. Se trata de un caso único en el que la joven recibía periódicamente una cantidad de dinero para su manutención como dote. En lo tocante a la dotación de Juan Tenorio el cabildo acordó que en conformidad a la cláusula testamentaria se le diese la renta de un año que, contados los intereses, le corresponderían 24.017 maravedíes. Así vemos que en caso de dotes de parientes no había restricciones y era respetada la voluntad del difunto.

De entre las dotaciones para entrar a convento del Hospital de la Misericordia, la más importante fue la destinada para las monjas de velo negro, proveniente de la voluntad testamentaria del capitán Miguel de Benavides a finales del siglo XVII.

\section{Las dotes para monjas del capitán Miguel de Benavides}

Este patronato en la Casa de Misericordia de Sevilla fue fundado con los bienes y rentas del capitán Miguel de Benavides el 2 de agosto de 1680, ante Bernardo García, escribano público de Sevilla. ${ }^{25}$ Don Miguel Beltrán de Benavides había nacido en Morillo de Riobeso, un pueblo logroñés, perteneciente al Obispado de Calahorra y había vivido muchos años en el virreinato de Nueva España de donde trajo una imagen de la Concepción Santísima de Nuestra Señora, que dio a la hermandad del Santísimo Sacramento de la Parroquia de Santa

23 AGI, Contratación, 429, 1652, Antonio Pérez Enríquez, natural de Sevilla y difunto con testamento en Lima. 1651-1652. Mandó fundar una capellanía en su patria y dotes para doncellas en la Misericordia; AGI, Contratación, 942, N.9, 1609, Autos sobre los bienes de Francisco de Alba, natural de Almendralejo. Falleció en Cartagena de Indias, con testamento. Deja una limosna para la cofradía de la Misericordia de Sevilla. Funda una capellanía en su tierra; AGI, Contratación, 200, N.1, R.4. Autos sobre bienes de difuntos: Diego de Azúa, natural de Deusto (Vizcaya), difunto en Veracruz. Herederos: Hospital de la Misericordia de Sevilla e Isabel de Maya, su esposa; AGI, Contratacion, 967ª, 1644-1648. Autos de los bienes del capitán Juan Sánchez de Lefa, que pide la Casa de Misericordia de Sevilla a quién los dejó por testamento, y vinieron de México

24 AHPS, Libro cabildo 4742, 14/04/1608.

25 AHPS. Legajo 22378. Hospital de la Misericordia. Libro del patronato del Sr. Capitán Miguel de Benavides, cuya fundación hizo y otorgó el Sr. don Nicolás Bucareli, su heredero fiduciario. Por escritura de fundación que pasó ante Bernardo García, escribano público de Sevilla.

Trocadero, no 28 (2016), ISSN 2445-267X, pp. 1-23 
María Magdalena de Sevilla. Era mariano y próximo a morir, entregó testamento cerrado, que otorgó ante Martín Andújar Alarcón, escribano público de Sevilla, en 31 de marzo de 1677, que con autoridad judicial se abrió y publicó ante el mencionado escribano el 2 de abril de 1677, fundando un patronato particular, delegando como albacea y heredero a don Nicolás de Bucareli. ${ }^{26}$

El donante legó rentas para mantener dotes entregadas a jóvenes pobres y huérfanas con el fin de que se casaran y otras dotes destinadas a hidalgas empobrecidas para entrar a un convento. De estas últimas nos ocuparemos en esta parte del artículo. El donante destinó una o varias dotes de mil ducados de oro a una o varias doncellas que tuvieran vocación para ser monjas descalzas, elegidas anualmente, pagándole de las rentas de su patrimonio que administraba el Hospital de la Misericordia. La cantidad de dotadas beneficiarias de la dote dependía de las rentas anuales, por lo que a veces este patronato podía dotar a más de una aspirante. También, el capitán Miguel de Benavides había dejado 500 ducados que debían entregarse anualmente al hospital del Espíritu Santo para ayuda a sus funciones. ${ }^{27}$

\section{Proceso de elección a nombramiento de dote a monja del patronato del capitán Benavides en la Casa Pía de la Misericordia}

El proceso comenzaba haciendo un llamado público, colocando edictos en la ciudad para que las candidatas presentaran solicitudes de participación a la dote. El fundador quiso que la selección de la dotada fuese en la misma conformidad y orden que se hacía para la elección de hermanos a la Misericordia cuando había una plaza vacante, conforme al capítulo tercero de la regla del hospital. Asimismo, los electores eran elegidos como si se eligiera a un miembro de la hermandad, colocando en una urna las cédulas con los nombres de los hermanos que asistieron al cabildo el día de la elección de la dotada. Los electores designados elegirían, a su vez, a la afortunada. Por ejemplo, en 1686, el padre mayor convocó a cabildo para cumplir y ejecutar la voluntad del capitán Miguel de Benavides. Un niño sacaba las cédulas de los elegidos. Aquel año, los hermanos o cofrades del Hospital de la Misericordia fueron veintitrés, de los cuales seis fueron elegidos para escoger a tres o cuatro jóvenes, entre las cuales el cabildo elegiría a la dotada. Los electores elegidos fueron los siguientes: Marqués de Carrión, don Luis Ignacio de Connique, Marqués de la Motilla,

26 ADPS. Legajo 23. Testamento de Miguel de Benavides. Hospital del Espíritu Santo.

27 AHPS, Libro cabildo 4755, 12/04/1705, s/f. 
don Fernando Caballero de Illescas, don Pedro Venegas de Córdova y don Pedro Leonardo de Ibarra.

Acto seguido, el padre mayor y los electores elegidos salieron del cabildo y después de haber realizado su elección, volvieron, habiendo propuesto a las siguientes candidatas: sor Luisa Martel, sor María de Cristo, sor Petronila de San Pedro, doña Catalina Luisa de Torres, doña María Román y doña María Agustina Juiri. Se volvió a votar, pero esta vez todos los hermanos que asistieron aquel día al cabildo votaron en secreto en cédulas que fueron echadas en una urna, eligiendo a dos de entre las candidatas elegidas por los seis hermanos electores. En total, veintitrés cuentas leídas que fueron los votos para la elección de las elegidas a una segunda vuelta. Sumando las dos veces que los hermanos votaron, el resultado fue el siguiente: sor Luisa Martel con dieciocho votos, sor María de Cristo con diecisiete votos, sor Petronila de San Pedro con tres votos, doña Catalina Luisa de Torres con cuatro votos, doña María Román con cuatro votos y doña María Agustina Juiri con ningún voto.

En esta elección tipo canónica, los votos fueron contados por el secretario del cabildo del Hospital de la Misericordia, teniendo como conclusión que Luisa Martel obtuvo dieciocho votos y sor María del Cristo, diecisiete. Luego se hicieron dos cedulillas con los mencionados nombres y fueron colocadas en una urna de plata y un niño sacó una que decía sor María de Cristo, que sería la elegida y nombrada a la dote. ${ }^{28}$ De esta manera fueron entregadas las dotes a monjas del patronato Benavides, entendiendo que la cantidad de dotes dependían de las rentas anuales del mencionado patronato, pudiendo entregarse de una a tres dotes de mil ducados al año (Anexo 1).

El hospital también tenía la obligación de velar por la familia directa del capitán Benavides, es decir de su hija y esposa que estaban recluidas en conventos. En 1698, doña María Micaela de Benavides, monja profesa en el convento de la Paz, dijo que su padre el capitán Miguel de Benavides había mandado al Hospital de la Misericordia pagar a su hija, o sea a ella, 300 ducados anuales durante su vida, y 200 ducados vitalicios a favor de su esposa Ana de Rivera que había fallecido. La hija de Benavides exigió a la Misericordia que le pagara 500 ducados anuales, y lo que le debía, pues su madre había renunciado a su pensión en favor de su hija desde hacía quince años. La junta de hacienda de la Misericordia se reunió con todos los papeles tocantes a esta materia y la fundación de este patronato para tomar una decisión. ${ }^{29}$ Después de dos meses, el cabildo del hospital indicó que la madre no había entrado en el convento de su hija como estaba estipulado en el

28 AHPS, Libro cabildo 4753, 15/08/1686, ff.120r-121r.

${ }^{29}$ AHPS, Libro cabildo 4754, 03/08/1698, f. 316v

Trocadero, $\mathrm{n}^{\circ} 28$ (2016), ISSN 2445-267X, pp. 1-23 
testamento del padre, y al no haber cumplido con esta cláusula no podía dar curso a lo que solicitaba. ${ }^{30}$ No se le concedió. Al cabo de nueve años, en 1707, la hija monja del capitán Benavides pidió ayuda económica:

"Una petición de doña María Micaela de Benavides, monja en el Convento de Nuestra Señora de la Paz, pidió limosnas de la donación del capitán miguel de Benavides, su padre, se le aplique cien ducados para salir de un ahogo grande en que se halla. Y se acordó de conformidad se comete al S. D. Juan Cid con la fundación". ${ }^{31}$

\section{LAS BEATAS}

La Misericordia no dotaba a beatas y ningún patronato lo pidió por lo que no podía destinarles rentas. Sin embargo se encuentran en la documentación consultada en el Archivo Histórico Provincial de Sevilla (AHPS) solicitudes de algunas beatas. La Misericordia encontró una estrategia para entregarles si no dotes al menos donaciones encubiertas como limosnas, provenientes de las muchas dotaciones que dejaban rentas libres para que el hospital las administrara y destinara como considerase conveniente.

Así por ejemplo, el 4 de marzo de 1635, el cabildo de la Misericordia había denegado una dote a Ana de Medina, prima hermana de Alonso Díaz de Villegas, el fundador de una dotación, porque la que la solicitaba había tomado y profesado el hábito de beata en la orden de San Francisco de Paula. El cabildo indicó que el estado de beata no era ingreso en religión, pues las dotes entregadas en la Misericordia eran para casadas y monjas. ${ }^{32}$ Ella se había opuesto a tal decisión por lo que pidió nuevos pareceres de teólogos.

La Misericordia accedió a que un grupo de personas diesen sus pareceres por escrito para confirmar o cambiar su parecer. Las personas elegidas fueron el oidor de la Real Audiencia de Sevilla don Antonio de Torres y Camargo, el doctor Urbano Pérez de Bueno y el licenciado don Gonzalo de Sotomayor. ${ }^{33} \mathrm{Al}$ cabo de un mes, la comisión acordó entregarle la dote por piedad y para evitar futuros pleitos y no porque le correspondiese por ser beata. La dote entregada era pequeña, sólo catorce

\footnotetext{
30 AHPS, Libro cabildo 4754, 03/10/1698, f. 323v.

31 AHPS, Libro cabildo 4755 (1700-1706), 01/05/1707, s/f

32 AHPS, Libro cabildo 4746 (1633-1636), Libro cabildo 4746 (1633-1636), ff. 234 r-v.

33 AHPS, Libro cabildo 4746 (1633-1636), 10/06/1635, ff. $278 \mathrm{r}-\mathrm{v}$
} 
mil doscientos maravedíes que era la mitad de la renta anual de la dotación. Cantidad entregada previa escritura de transacción que reemplazaría a una carta dotal. ${ }^{34}$

Otra parienta de Alfonso Díaz de Villegas pidió una dote de parentesco “por ser mujer de edad que quiere ser beata y profesar y que haciendo tal profesión adquiere esta dote como religiosa". ${ }^{35}$ En este caso, el cabildo le concedió tal petición también a modo de limosna porque no le correspondía por querer convertirse en beata.

\section{DOTES ENTREGADAS POR LA MISERICORDIA A HUÉRFANAS ABANDONADAS EN CONVENTOS, COFRADÍAS Y OTRAS INSTITUCIONES RELIGIOSAS}

Otra práctica era dotar a huérfanas que estaban al cuidado de instituciones religiosas. Las más importantes dotes que entregó la Misericordia fueron de los patronatos de Ana de Rivera y de Miguel de Benavides. El primer patronato mencionado entregaba dotes de 50 ducados a una doncella huérfana que nombraba la rectora o madre priora del convento del Espíritu Santo, institución conocida como colegio de las Niñas de la Doctrina, en la collación de San Juan de la Palma, en Sevilla, anualmente. La limosna más temprana para este fin según la documentación primaria es de $1569 .{ }^{36}$ La rectora nombraba a una joven de las que se criaban en ese convento ${ }^{37}$ o prefiriendo a las que se criaban allí para que estando casadas y veladas se le pagara la dote. ${ }^{38}$ Sin embargo, esta renta no daba lo suficiente y se pagaba a base de juros. ${ }^{39}$ Esta dote estuvo vigente desde mediados del siglo XVI al XVIII. ${ }^{40}$ Por ejemplo, en 1634, la priora Catalina de Pineda pidió que fuese nombrada a una dote de Ana de Rivera una doncella que servía y vivía en el convento llamada Felipa de Santiago. El cabildo de la Misericordia lo aceptó y se la asentó en los libros. ${ }^{41}$ En 1704, la priora María Teresa de Jesús pidió el nombramiento de una dote del patronato mencionado. La Misericordia admitió que se le pagara si había rentas en la dotación. ${ }^{42}$

\footnotetext{
34 AHPS, Libro cabildo 4746 (1633-1636), f. 293 r y f. 294 v. Acuerdo sobre la pretensión de doña Ana de medina beata sobre que se le den 14.200 maravedíes que se le den por la dotación de Alonso Díaz de Villegas por escritura de transacción. Parienta en segundo grado, prima hermana y porque dejo dote a parientas hasta el cuarto grado y no le querían dar por ser beata según pareceres de teólogos y juristas pero el hospital le dio para evitar futuros pleitos y por piedad. La mitad de la renta anual.

35 AHPS, Libro cabildo 4746 (1633-1636), f.124 r.

36 AHPS, 4738, Libro cabildo, febrero 1567. AHPS.4739, 1568--1590, s/f. nov de 1569: Limosna a las niñas de la doctrina

${ }^{37}$ AHPS, Libro cabildo 4749 (1643-1649), 05/01/1648, f. 290 r.

38 AHPS, Libro cabildo 4765 (1756-1761), 01/03/1760, f. 249v

39 AHPS, Libro cabildo 4746 (1633-1636), 02/06/1535, f.259r

40 AHPS, Libro cabildo 4769(1778-1786) 06/ 07/1783, f.265v.

41 AHPS, Libro cabildo 4746 (1633-1636), 1/10/1634, f. 184 r.

42 AHPS, Libro cabildo 4755, 04/05/1704, s/f.
}

Trocadero, no 28 (2016), ISSN 2445-267X, pp. 1-23 
El segundo patronato mencionado el del capitán Miguel de Benavides entregó dotes destinadas específicamente a jóvenes pobres que trabajaban como "enfermeras" por al menos un año consecutivo en el hospital de las Cinco Llagas o de la Sangre de Sevilla, prefiriéndose a las que en ejercicio de este trabajo hubiesen enfermado. ${ }^{43}$ Recibirían cincuenta ducados de dote, luego que se casasen. En este caso, para el nombramiento de dote era necesario certificación de curación o informe de persona de todo crédito que bajo juramento comunicase al Sr. padre mayor de la Casa de la Misericordia del mal estado en que se hallaba la aspirante a la dote. Este detalle de dotar a jóvenes que cuidando a enfermos se hubiesen enfermado y curado fue un detalle peculiar, teniendo en cuenta que nadie se había ocupado de esto antes, es decir de alguna manera premiar a las que en su afán de atender a los enfermos habían contraído alguna enfermedad. Este patronato se fundó bajo la protección y amparo de la Serenísima reina de los ángeles María señora nuestra concebida sin mancha de pecado original, es decir, la Inmaculada Concepción. Debido a lo cual la nombrada tenía la obligación de ir personalmente a la iglesia parroquial de Santa María Magdalena de Sevilla a visitar a la imagen de Nuestra Señora de la pura y limpia concepción, que estaba colocada en la capilla del sagrario de la iglesia, que el fundador del patronato había traído de México, dándole gracias en reconocimiento de este beneficio, encomendando a Dios al dotador y a los patronos y administradores del patronato. En caso que la nombrada no fuese vecina, ni tuviese residencia en Sevilla, tenía que ir a visitar la iglesia parroquial del lugar donde vivía.

Sin embargo, la Misericordia no se preocupó en hacer cumplir esta dotación. El notario del hospital de la Sangre tenía que acercarse a la Misericordia con documentación que sustentara que las jóvenes habían trabajado el tiempo necesario. Así, en 1685, el licenciado don Andrés Palomo Curado, notario apostólico y secretario del hospital de la Sangre, presentó una certificación del tiempo que una doncella había servido asistiendo a las pobres en el mencionado hospital, más de tres años. La joven se llamaba Casilda de Lara, hija de Antonio de Lara y de Antonia de la Peña, para la cual pedía se la nombrara en una de los dotes que para tales doncellas había dejado el capitán Miguel de Benavides. El cabildo acordó de conformidad entregarle una dote de cincuenta ducados de la mencionada dotación. ${ }^{44}$ Se debe remarcar que la única dotación en la Misericordia que destinó dinero para entregar dotes a mujeres que trabajaban cuidando enfermos fue la del capitán

${ }^{43}$ RIVASPLATA VARILLAS, Paula Ermila. Las doncellas de dote del Hospital de las Cinco Llagas de Sevilla. Una lectura en clave de género. Berlín, Editorial Académica Española, 2011. RIVASPLATA VARILLAS, Paula Ermila. "Dotes de doncellas pobres sevillanas y su influencia en la ciudad de Lima", en Revista de Indias, Vol. LXXV, $\mathrm{n}^{\circ} 264$ (Mayo-agosto, 2015), pp. 351-387.

44 AHPS, Libro cabildo 4753, 04/04/1685, f. 57r. 
Benavides. También, este patronato entregó dotes a huérfanas criadas del convento colegio de Niñas de la Doctrina, ubicada en el Espíritu Santo de Sevilla.

Por otro lado, se debe recordar que el patronato de Benavides, también, dotaba con mil ducados a hidalgas que entraban a convento. En este caso, la Misericordia sí cumplía con entregar anualmente una dote de mil ducados a una monja de velo negro, pero no se cumplió la voluntad de Benavides de dotar a mujeres pobres que trabajaban en el hospital de la Sangre de Sevilla. Incluso, una de estas dotadas fue a la misma Misericordia a exigirlo, ante la desidia de las autoridades. Por eso, en 1686, Juana Dionisia de la Fuente indicó que estaba sirviendo en el hospital de la Sangre de Sevilla más de tres años como constaba en una certificación que presentaba del letrado del hospital de las Cinco Llagas el licenciado don Andrés Palomo. Esta joven exigió su dote del patronato Miguel de Benavides y se acordó que ajustada la cuenta de esta dotación y habiendo residuo para ello se la nombrara y la contaduría diera cuenta de ello. ${ }^{45}$ Los esposos de las dotadas, también, fueron al Hospital de la Misericordia a pedir que se les pagara la dote a sus esposas, llevando documentos correspondientes, expedidos por el área de convalecencia del Hospital de la Sangre, como se puede observar en la tabla adjunta.

45 AHPS, libro cabildo 4753, 13/01/1686, f. 95v 


\begin{tabular}{|c|c|c|c|c|c|c|}
\hline \multicolumn{7}{|c|}{$\begin{array}{l}\text { Tabla } 1 \\
\text { Datos de doncellas que habían trabajado en el Hospital de las Cinco Llagas de Sevilla como } \\
\text { enfermeras, otorgados por el patronato Benavides, fundado en la casa de Misericordia de Sevilla }\end{array}$} \\
\hline Nombre & Edad & Procedencia & $\begin{array}{l}\text { Tiempo } \\
\text { que } \\
\text { trabajó la } \\
\text { doncella }\end{array}$ & $\begin{array}{l}\text { Cantidad } \\
\text { entregada }\end{array}$ & $\begin{array}{l}\text { Nombres del esposo y } \\
\text { del } \\
\text { escribano público }\end{array}$ & Nombre de los padres \\
\hline \multirow[t]{3}{*}{ Juana Dionisia } & \multirow[t]{3}{*}{25} & \multirow[t]{3}{*}{ Triana } & \multirow[t]{3}{*}{$\begin{array}{l}1681 \\
1685\end{array}$} & \multirow[t]{3}{*}{$\begin{array}{l}50 \\
\text { ducados }\end{array}$} & \multirow{3}{*}{$\begin{array}{l}1698 \\
\text { Juan Martín (Triana) } \\
\text { Oficio: Maestro } \\
\text { barreno } \\
\text { Llevó testimonio } \\
\text { para la casa de la } \\
\text { Misericordia } \\
\text { del área Convalecencia } \\
\text { del hospital de las } \\
\text { Cinco Llagas } \\
1698\end{array}$} & $\begin{array}{l}\text { Juan Garrido de la } \\
\text { Fuente } \\
\text { Catalina Ruiz }\end{array}$ \\
\hline & & & & & & $\begin{array}{l}\text { Nombramiento de dote } \\
\text { de la Misericordia } \\
1698\end{array}$ \\
\hline & & & & & & $\begin{array}{l}\text { Año que pagó la } \\
\text { Convalecencia } \\
1698\end{array}$ \\
\hline $\begin{array}{l}\text { Casilda de } \\
\text { Lara }\end{array}$ & 24 & Palma & $\begin{array}{l}1682 \\
1685\end{array}$ & $\begin{array}{l}50 \\
\text { ducados }\end{array}$ & $\begin{array}{l}1691 \\
\text { Fernando de Rivas } \\
\text { Llevó testimonio para } \\
\text { la casa de la } \\
\text { Misericordia de que su } \\
\text { esposa trabajó en el } \\
\text { área de ra } \\
\text { Convalecencia del } \\
\text { hospital de las Cinco } \\
\text { Llagas. Se le pagó la } \\
\text { dote en } 4 \text { partidas o } \\
\text { partes } \\
\text { Notario: } \\
\text { García }\end{array}$ & $\begin{array}{l}\text { Antonio de Lara } \\
\text { Antonia de la Peña }\end{array}$ \\
\hline
\end{tabular}

Estos fueron los dos únicos casos documentados tanto en el archivo del Hospital de la Sangre como en el de la Misericordia de entrega de dotes a jóvenes que trabajaban cuidando enfermas. En la documentación del Hospital de la Sangre en el Archivo de la Diputación Provincial de Sevilla no se encuentra otra petición de dote a este patronato ni en documentación del Hospital de la Misericordia en el Archivo Histórico Provincial de Sevilla consta que se hubiesen entregado más dotes de este tipo. ${ }^{46}$

Aparte de las dotaciones mencionadas, la dotación de Francisco de Ordaz dotaba a niñas sirvientes entregando cada año seis vestidos a seis de estas niñas del convento de monjas del Espíritu Santo de Sevilla. ${ }^{47}$ También, en la Misericordia, la única cofradía de

46 ADPS. Legajo 188. Libro donde se asientan las doncellas que salen del hospital de la Sangre de Sevilla. Año de 1651. Nombradas en dotes, f. 1 r. Con solo una excepción, en 1710, el administrador del hospital de las Cinco Llagas, don Julián Platas, llevó testimonio de las cláusulas para hacer diligencia en la casa de la Misericordia y hacer cumplir esta voluntad de dotar una doncella del hospital, pero no lo logró.

47 AHPS, Libro cabildo 4766(1756-1761), 03/02/1761, f. 8r 
oficios que entregaba dotes a sus doncellas fue la de los artistas plateros que lo hacía a través de la voluntad testamentaria de su bienhechor Miguel Gerónimo de Monegro. ${ }^{48}$

Se tiene constancia de que la Misericordia acogía a niñas abandonadas por sus padres o huérfanas que dejaban en sus puertas y a niñas víctimas de violencia familiar La institución las criaba a través de mujeres de cualquier estamento social que solicitaban hacerlo y pedían "hijar a una niña que crió el hospital". En 1567, una mujer de carpintero pidió que quería hacerse cargo de cualquier niña de las que criaba el hospital y tomarla por ahijada. La Misericordia también pedía a hidalgas que criasen alguna huérfana por caridad. Así ese mismo año doña María de Esquivel dijo que el mayordomo Diego de Gómez le había entregado una niña "que habían echado a la puerta del dicho hospital" para que la criase. Y lo hizo por "hacer caridad e limosna" durante catorce años y que pedía ser admitida a una dote. Estas niñas al crecer eran las preferentes en recibir dotes cuando lo solicitaran previa visita, admisión a dote y casamiento. ${ }^{49}$ Otra niña cuya madre había sido asesinada por su padre, fue criada por el hospital a través de su abuela a quien le entregó el dinero necesario para hacerlo y que al llegar a edad casadera el hospital recibió un ajuar de matrimonio $^{50}$

El recogimiento de San Miguel había sido fundado por el arzobispo Pedro de Tapia en 1654. Al año siguiente, este recogimiento fue declarado el único de la ciudad de Sevilla, sustituyendo en el lugar y derechos que habían tenido los demás recogimientos y emparedamientos, que había habido en ella. En 1655, la Misericordia pagaba aún algunas mandas de dotes y de dineros del recogimiento que hubo cerca del convento de monjas del Dulce Nombre de Jesús que se había extinguido hacía más de 30 años (1625). El nuevo recogimiento de San Miguel pedía a la Misericordia que todos los legados que los testadores dejaron a las arrepentidas o convento de recogidas del Dulce Nombre de Jesús le fuesen pagados como si a él se hubieran dejado. Ante esta situación fue encargado Francisco Ortiz

\footnotetext{
48 AHPS, Libro cabildo 4755 (1626-1630), 08/03/1626. En este cabildo se hizo relación de una petición de María de Sosa nombrada por los plateros en el dote de Miguel Gerónimo de Monegro bienhechor en el cabildo de esta casa en virtud de él está casada y velada acordaron que se escriba este desposorio en los libros y se dé comisión al tesorero de esta casa para que tome señas a su marido; AHPS, Libro cabildo 4747(16361639) $02 / 09 / 1637$, f. 94 r.

49 AHPS, Libro cabildo 4738, 1566-1578, febrero 1567, f. 75 r. AHPS.4738, 1566-1578, abril 1567, ff. 96v97r; AHPS, Libro cabildo 4738, 1566-1578, abril 1568, f. 164v. Dé asiento a la niña que este hospital ha criado que se llama Ángela.

50 AHPS.4737, 1552-1561, 03/03/1560, f. 299v. "En este cabildos se vido una petición de Marina Ruiz mujer de Francisco de Mesa, cordonero, difunto vecino a la Magdalena por el hospital de San Bartolomé que es a la puerta de Triana, en que dice que este hospital se le recibió una hija suya nombrada Francisca de Mesa la cual mató su marido falsamente y que dejó una hija nombrada María de Mesa que la dicha Marina Ruiz tiene consigo y que este hospital le ayudo para criarla y porque es de 14 años pide la reciban por hija de esta casa y el dicho cabildo mandó que se haga como lo pide la dicha Marina Ruiz atento que consta que es verdad lo de su contenido y que el sr. padre mayor mande visitar la dicha doncella y siendo conforme a nuestra regla dé el ajuar como se acostumbre".
}

Trocadero, $\mathrm{n}^{\circ} 28$ (2016), ISSN 2445-267X, pp. 1-23 
de Godoy para que diese su parecer al cabildo con los testamentos e informe de la cuenta y en la primera comisión se viese y resolviese. Finalmente fue aceptada esta petición. ${ }^{51}$

La Casa Pía de la Misericordia recibía voluntades testamentarias, consistentes en otorgamiento de becas renovables de estudios de 100 ducados a jóvenes varones en forma anual. $^{52}$

\section{DOTES PARA REMEDIAR MUJERES ARREPENTIDAS Y QUE HABÍA VIVIDO EN EL PECADO}

La Misericordia servía para canalizar obras pías destinadas a otras instituciones. La viuda del escribano público Francisco Hurtado, Juliana Sarmiento, murió el 7 de septiembre de 1621 y en su testamento declaró como único heredero a un patronato instituido por ella para ayudar a casar a antiguas mujeres descarriadas. Este patronato estaba constituido por un presidente jesuita, un vicepresidente mercedario descalzo, fiscal, mayordomo, tesorero y procurador. ${ }^{53} \mathrm{La}$ institución que albergó este patronato fue la antigua hermandad del Cristo de la Misericordia y Nuestra Señora de Belén en el convento de Mercedarios Descalzos de San José de Sevilla.

Las dotes de mujeres descarriadas entregadas por la Misericordia provenían del legado que dejó el hermano Gabriel Luis desde la primera mitad del siglo XVII y constituyó el primero con el objetivo de remediar a mujeres arrepentidas que vivían recluidas en el monasterio del Dulce Nombre de Jesús en Sevilla. El proceso consistía en que dos hermanos de la Misericordia iban a nombrar y visitar a las mujeres arrepentidas que habían vivido en pecado y estaban recogidas en un cuarto del mencionado convento de monjas que estaba en la collación de San Vicente. Los hermanos solían nombrar a diez mujeres. El número dependía de la renta que tenía aquel año la dotación. Los hermanos tomaban sus datos personales, sus nombres, la de sus padres, lugar de bautismo y señas personales. ${ }^{54} \mathrm{La}$ documentación más temprana de este patronato indica que entregaba dotes a mujeres arrepentidas que habían vivido en el pecado desde $1634 .{ }^{55} \mathrm{El}$ año mencionado el cabildo recibió tres peticiones, una de Francisca Josepha, otra de Francisca de Ribera y otra de María Magdalena. Mujeres que decían estar en pecado y que se querían

\footnotetext{
51 AHPS, Libro cabildo 4751, 11/07/1655, f.7r.

52 AHPS, Libro cabildo 4746 (1633-1636), 21/04/1635, f. 258 r-v; AHPS. Libro cabildo 4746 (1633-1636), f.259 r. Dote de estudios a joven 100 ducados anuales.

${ }^{53}$ RUIZ BECERRA, María Teresa. "La antigua Hermandad del Cristo de la Misericordia y Nuestra Señora de Belén en el Convento de Mercedarios Descalzos de San José de Sevilla" en $V$ simposio sobre hermandades de Sevilla y su provincia. Sevilla, 2004, pp. 139-167, p. 142.

${ }_{54}$ AHPS, Libro cabildo 4747 (1636-1639) 04/04/1636, f. 63v y f. 64r.

55 AHPS, Libro cabildo 4746 (1633-1636), 21/05/ 1634, f.138r.
} 
"convertir, arrepentidas de sus vidas", porque tenían personas que con ellas se casarían. De esta manera, en esta sociedad el solo hecho de tener personas con que casarse, ya las liberaba de vivir en pecado. Por lo cual, la Misericordia les daba dotes. Dos hermanos fueron a verlas, Juan de Espinosa Salvago y Francisco de Ocaña, los que confirmaron ser de la calidad referida, les tomaron las señas físicas para admitirlas en una dote de Gabriel Luis. Los mismos hermanos tenían que estar presentes como testigos de que se realizarían los desposorios.

Es interesante indicar que las dotes dadas a "las pecadoras" eran entregadas a sus respectivos esposos por haberlas "salvado". Incluso, los hermanos buscaban hombres para que se casaran con las arrepentidas, ofreciéndoles la dote y algunos por pobreza accedían. De esta manera, la Misericordia ofrecía dinero para que se casaran con pecadoras para que así se redimiesen.

Indican las fuentes que estos hombres ejercían oficios marginales. La idea de que el matrimonio liberaba a la prostituta era una idea muy difundida en la modernidad. Así en 1634, Esteban Pérez de la Sosa indicó que se había casado a instancia del hermano Andrés de Medina con una mujer pecadora para recibir la dote y accedió por pobreza para comprar una cama. Se comprobó que era verdad que el hermano Andrés de Medina había prometido una dote para sacar de pecado a Francisca. Se tomó razón de la dote en los libros y se pagó la dote al esposo: ${ }^{56}$

"Viose una petición de Catalina de Escalera mujer que dice vivir en pecado y que se quiere recoger en servicio de Dios Nuestro Señor y casarse con Lázaro de Ribera que es oficial de lapidario. Pedía se le diese de limosna para casarse un dote de la dotación de Gabriel Luis y se acordó que esta petición se remite a el Sr. Don Juan de Pineda Salvago para que su merced visite a la dicha Catalina de Escalera y se informe si es mujer de las calidades que requiere la disposición de las dotes del dicho Gabriel Luis. Y siéndolo tome las señas de su persona y se halle presente a su desposorio el cual escriba conforme a la orden y por ella la contaduría le dé libranza al desposado para que se le pague". ${ }^{57}$

Estas mujeres tenían signos de violencia en sus cuerpos, caras golpeadas y narices quebradas. Había entre las mujeres arrepentidas muchas maltrechas. Las fuentes nos indican que una tenía una herida en la nariz y otra en la frente. ${ }^{58}$ En 1641 , cuando se efectuó la entrega de dotes a mujeres arrepentidas, de once, seis estaban lastimadas con heridas: "señal pequeña en la frente de caída", "señal de herida en la frente junto al pelo", "señal de quemadura en el lado derecho de la barba", "señal de herida a el pelo en la

\footnotetext{
56 AHPS, Libro cabildo 4746 (1633-1636), 21/05/1634, ff. 139r-v.

57 AHPS, Libro cabildo 4746 (1633-1636), 18/06/1634, f.145v. y f.146r. Petición de Catalina de Escalera pide la dote de las recogidas de Gabriel Luis. 58 AHPS, Libro cabildo 4747 (1636-1639), 17/04/1638, ff. 161r-v.
}

Trocadero, no 28 (2016), ISSN 2445-267X, pp. 1-23 
frente", "una señal en la nariz al lado derecho de caída" y"la nariz quebrada". 59 Por ejemplo, una arrepentida que solicitó una de estas dotes, tenía señas de maltrato físico en el cuerpo:

"Petición de dote de Gabriel Luis a María López mujer que decía ser pecadora y que quería poder servir a nuestro señor y apartarse del pecado y casarse haciendo la merced esta casa de darle una dote del que se da a semejantes mujeres---- y siendo mujer pecadora y que está en mal estado le tomé las señas de su persona". ${ }^{60}$

Mujeres que decían ser pecadoras y de malvivir y que para arrepentirse de su pecado querían tomar estado casándose y que para conseguirlo pedían las dotes que la Misericordia daba a estas mujeres con el objetivo de que "salgan de su situación, casándose...". ${ }^{61}$

Otras cinco personas destinaron bienes y parte de sus rentas para "redimir" a las arrepentidas. En 1639, tres personas habían donado rentas en la Misericordia para dotar a mujeres arrepentidas según una relación de la contaduría. Ese año se entregaron en total doce dotes a estas mujeres: ocho dotes de mujeres convertidas de Gabriel Luis de trece mil maravedíes, dos dotes de Bartolomé de Perea de trescientos reales cada uno y dos dotes de Juan López de la Vera de cincuenta ducados. Tres hermanos fueron al cuarto de las recogidas del Convento del Dulce Nombre de Jesús y nombraron a las mujeres que tenían las características indicadas que el testador dispuso. Los visitadores que elegían no eran los que asistían a sus casamientos. Las otras dotes destinadas a estas mujeres, la de Juan López de la Vera y Leonardo de la Cueva debían ser ajustadas. ${ }^{62} \mathrm{Al}$ cabo de once días, se nombró a doce mujeres recogidas. ${ }^{63}$

Las personas que se dedicaban a servir al prójimo esperaban que la Misericordia les entregase una dote, a modo de deferencia, para dotar a alguna mujer que lo necesitara. Una de las más demandadas era dotar a prostitutas para sacarlas de la situación en la que vivían. La madre mayor María de Meneses pidió a la Misericordia una dote para una mujer de las recogidas y se acordó que habiéndose casado la elegida, se le diera como se acostumbraba. ${ }^{64}$ El cabildo acordó que se le diese la dote que pedía si tenía "cabimento" o dinero la dotación. ${ }^{65}$

\footnotetext{
${ }^{59}$ AHPS, Libro cabildo 4748 (1636-1639), 07/04/1641, f. 139v.

${ }^{60}$ AHPS, Libro cabildo 4746(1633-1636), $184 \mathrm{r}$.

${ }^{61}$ AHPS, Libro cabildo 4746(1633-1636), f.195 r.

62 AHPS, Libro cabildo 4747(1636-1639)16/04/1639, f. $268 \mathrm{r}$.

63 AHPS, Libro cabildo 4747(1636-1639)27/04/1639, f. 271r y f.272r.

${ }^{64}$ AHPS, Libro cabildo 4750(1649-1655) de 04/02/1652, f. 211 r.

65 AHPS, Libro cabildo 4750(1649-1655), 2/02/1653.
} 
A mediados del siglo XVII, las mujeres perdidas estaban en el recogimiento de San Miguel. Las mujeres de élite también querían redimir prostitutas. En 1658, María de la Cruz y Meneses pidió hacer nombramiento de una dote de la dotación de Gabriel Luis en María Muñoz recogida en el recogimiento de San Miguel que estaba consentida a casar con el hortelano Diego González. El diputado del recogimiento debía presentar certificación del recogimiento y que pagara la orden. ${ }^{66}$ Asimismo, la elegida a otra dote fue María de Castillo mujer recogida que quería casarse con el chocolatero Luis de Valenzuela. ${ }^{67}$ Las señoras de élite iban al recogimiento a buscar chicas para redimir. Así, María de la Cruz y Meneses fue al recogimiento de las recogidas del arcángel San Miguel donde estaba Francisca María que la tenía concertada a casar con el marinero Antonio Domínguez con quien acordó que acudiese a la contaduría y despachara la dote que pedía. ${ }^{68}$

Una víctima de violación fue obligada a casarse con su violador. La Misericordia consideró a una mujer estuprada como una mujer perdida y arrepentida porque le concedió una dote de Gabriel Luis a pedido de un hermano de la casa, llamado Juan Antonio de Arteaga, que en 1663, solicitó el nombramiento de una dote para casar a Leonor María con Alonso López que era oficial de pastelero, el que la estupró, acordándose que habiendo caudal en la dotación de Gabriel Luis se le diese una dote de trece mil maravedíes. ${ }^{69}$

\section{A MODO DE CONCLUSIÓN}

Hasta ahora, la investigación en cuanto a este tema se ha inclinado hacia el estudio de dotes de nobles e hidalgas y se han ignorado las dotes de las doncellas pobres, a pesar de la ingente documentación archivística. Esto nos hace pensar que el estímulo por investigar la historia de la mujer disminuye a medida que desciende la condición social y económica del objeto de estudio. Hay que tener en cuenta que la diferencia de las dotes delegadas por los patronatos a hidalgas, trabajadoras de hospital y prostitutas es abismal. Lo que es clara muestra de la tendencia a la perpetuación de los estamentos sociales por los donadores. Así, el patronazgo del capitán Benavides otorgado para su administración a la Misericordia entregaba dotes gratuitas sin mediar trabajo para conseguirlo a monjas hidalgas mil ducados $(100 \%)$ y dotes a descendientes de criadas de donadores que fluctuaba entre doscientos ducados $(15.38 \%$ ) y cien ducados $(7.69 \%)$, mientras que una dote de doncella que trabajaba por tres años en el hospital y la de una huérfana sólo era de cincuenta ducados (3.85\%) y

\footnotetext{
66 AHPS, Libro cabildo 4751, 13/01/1658, f.104r.

${ }^{67}$ AHPS, Libro cabildo 4750(1649-1655), 16/03/1653, f. 279v.

68 AHPS, libro cabildo 4751, 03/02/1658, f.106r.

69 AHPS, libro cabildo 4751, 03/06/1663, f.259v
}

Trocadero, $\mathrm{n}^{\circ} 28$ (2016), ISSN 2445-267X, pp. 1-23 
las dotes de prostitutas se reducía a prácticamente la mitad de la última dotación, aproximadamente veintidós ducados. Sin embargo, no se debería olvidar que las dotes más altas entregadas por la Misericordia a monjas hidalgas eran bajas, si la comparamos con dotes de casadas de esos mismos estamentos sociales, lo que hace aún más distante la diferencia dotal entre los diversos estamentos.

Es necesario indicar que así como en el estamento alto una buena dote rompía barreras sociales y raciales, lográndose realizar matrimonios donde el marido "olvida" o "perdona" el hecho de que la prometida no tuviese todas las cualidades deseadas: que sea blanca, virgen y de buena familia, aportando dotes superiores al promedio si querían alcanzar la seguridad del estado matrimonial. Esta práctica fue emulada por los estamentos bajos al punto que una virgen blanca, de buena fama y trabajadora mereciese mayor reconocimiento a través de una dote de cincuenta ducados, mientras que una prostituta recluida en un recogimiento recibía la mitad de la anterior, una mínima dote, para lograr un matrimonio que la remediase simbólicamente ante la sociedad.

En cuanto a las dotes a religiosas, el patronato Miguel de Benavides prefirió dotar a monjas descalzas de Sevilla, con una dotación de mil ducados a cargo de la Casa de la Misericordia. En el Archivo Histórico Provincial de Sevilla se han encontrado listas de estas dotadas, sin embargo este patronato solo dotó a dos doncellas pobres que trabajaban en el Hospital de la Sangre de Sevilla. Para este patronato, la dotación de doncellas pobres para el matrimonio se trató de un pío deseo que sólo se pudo llevar a cabo cuando hubiera rentas para ello, a modo de residuo, una vez que se hubiesen cumplido la primera voluntad del fundador del patronato que fue dotar a doncellas hidalgas para tomar estado de religiosa. Esto nos indica la consciencia de estamento que tenía la élite de ayudar sobre todo a sus iguales. Se temía que los hidalgos cayeran en la pobreza, pudiendo perder el honor y fuesen motivo de escarnio y mal ejemplo social.

Como conclusión es importante indicar que la Casa Pía u Hospital de la Misericordia de Sevilla cumplió un papel transcendental de protección a la mujer pobre y desamparada cualquiera fuera su estamento. Existía una consigna a seguir en el Antiguo Régimen, las hidalgas si no se podían casar bien, eran protegidas ingresando en conventos mientras que las pobres se las orientaba al matrimonio. Las dotes de las primeras eran indudablemente mucho más altas que las segundas. Ambas terminaban amparadas en instituciones fuesen eclesiásticas o familiares. Por eso las beatas no recibían dotes sino limosnas porque no encajaban en ninguna de estas dos instituciones patriarcales. 
Finalmente, en este artículo se observa el importante papel que cumplió la Misericordia como intermediario para proteger a hidalgas con mínimas dotes para ingresar a conventos como monjas, a jóvenes abandonadas que acogía y protegía, ubicándolas en familias como criadas y redimiendo a prostitutas ante la sociedad. El sistema permitía que la comunidad en su conjunto participara no solo con la entrega de rentas para el mantenimiento de estas dotes por voluntades testamentarias, sino también ofreciéndose a cuidar huérfanas y otros solicitando poder nombrar a las elegidas a dote. 


\begin{tabular}{|c|c|}
\hline \multicolumn{2}{|r|}{$\begin{array}{c}\text { Anexo } 1 \\
\text { Año y número de hidalgas dotadas con mil ducados para ingresar a convento y convertirse en } \\
\text { monjas descalzas del patronato } \\
\text { del capitán Miguel de Benavides }\end{array}$} \\
\hline Año & Número de monjas descalzas elegidas para recibir una dote \\
\hline 1686 & Elección de una monja descalza del patronato del capitán Miguel de Benavides. \\
\hline 1687 & Elección de una monja descalza del patronato del capitán Miguel de Benavides. \\
\hline 1689 & Elección de una monja descalza del patronato del capitán Miguel de Benavides. \\
\hline 1701 & $\begin{array}{l}\text { Elección de tres monjas descalzas a dotes de mil ducados cada una de la dotación del capitán } \\
\text { Miguel de Benavides durante el cabildo extraordinario del } 12 \text { de julio de } 1701 \text {. Al mencionado } \\
\text { cabildo asistieron veinte hermanos y faltaron dos. Los electores de la primera dote fueron: don } \\
\text { Fernando Caballero, don Jerónimo de Aranda, Conde de Torrejón, don Jerónimo de Céspedes, } \\
\text { don Juan de Godoy y don Pedro López Álamo. Los seis electores pasaron a la contaduría a } \\
\text { proponer las doncellas candidatas y fueron las siguientes: doña Isabel de Salvatierra, doña Juana del } \\
\text { Santo Sacramento, doña Julia de Saravera, doña Juana del Castillo y doña Manuela de Tapia. Salió } \\
\text { por elección canónica doña Isabel de Salvatierra y Juana del Santísimo Sacramento. Un niño lo } \\
\text { decidió, sacando de la urna una cédula que decía Salvatierra, la que obtuvo la dote. De la misma } \\
\text { manera se eligió a las otras dos dotadas. }\end{array}$ \\
\hline 1703 & $\begin{array}{l}\text { Elección de cuatro religiosas descalzas a dotes de mil ducados cada una de la dotación del capitán } \\
\text { Miguel de Benavides durante el cabildo general del } 6 \text { de mayo de } 1703 \text {. Un niño sacó de una urna } \\
\text { seis cédulas de seis electores que junto al padre mayor pasaron a la contaduría donde votaron y } \\
\text { trajeron al cabildo seis propuestas. Los veinte hermanos eligieron, separando a las que tenían más } \\
\text { votos. Se volvió a votar y se separó a la que tenía más votos y así dos veces más. Al final un niño } \\
\text { sacó de la terna a la ganadora. El mismo procedimiento se utilizó para obtener tres dotadas más. }\end{array}$ \\
\hline 1705 & $\begin{array}{l}\text { Elección de una religiosa descalza a una dote de mil ducados de la dotación del capitán Miguel de } \\
\text { Benavides. Los hermanos Pedro Luis de Ávila, Fernando caballero de Illescas, Marqués de Val de } \\
\text { Osera, Esteban Arpe, Manuel Velásquez y Pedro Venegas de Córdova salieron con el padre mayor } \\
\text { e hicieron su elección, regresaron al cabildo trayendo las propuestas siguientes: doña Luisa Martel } \\
\text { de Porras, doña Beatriz de Monsibay, Catalina Luisa, doña María Manuela Matienzo, doña María } \\
\text { Román y doña Teresa María Castellar } \\
\text { Luego, se procedió a votar por votos secretos en cedulillas que se echaron en la urna y sacadas se } \\
\text { contaron y se hallaron trece cédulas de las cuales tuvieron los votos siguientes } \\
\text { Doña Luisa Martel de Porras: trece votos } \\
\text { Doña Beatriz de Monsibay: ocho votos } \\
\text { Doña Catalina Luisa: tres votos } \\
\text { Doña María Manuela Matienzo: un voto } \\
\text { Doña María Román: un voto } \\
\text { Doña Teresa María Castellar: un voto } \\
\text { Luego se regularon los votos, saliendo por elección canónica con trece votos doña Luisa Martel y } \\
\text { con ocho votos doña Beatriz Monsibay. Ambas opciones entraron en un ánfora y lo decidió un } \\
\text { niño quien sacó una boletilla de plata de las dos que decía doña Beatriz de Monribay quien quedó } \\
\text { nombrada, a pesar de tener menos votos. La elegida pidió ampliación de tiempo para entrar en } \\
\text { convento porque estaba enferma con fiebres. }\end{array}$ \\
\hline 1761 & $\begin{array}{l}\text { Elección de una religiosa descalza a una dote de mil ducados de la dotación del capitán Miguel de } \\
\text { Benavides. }\end{array}$ \\
\hline 1785 & $\begin{array}{l}\text { Elección de una religiosa descalza a una dote de mil ducados de la dotación del capitán Miguel de } \\
\text { Benavides. A esta convocatoria se presentaron veintidós pretendientes. }\end{array}$ \\
\hline 1815 & $\begin{array}{l}\text { Elección de una religiosa descalza a una dote de mil ducados de la dotación del capitán Miguel de } \\
\text { Benavides en } 1815 \text {. }\end{array}$ \\
\hline & $\begin{array}{l}\text { entes: AHPS, Libro cabildo 4753, 14/12/1687, f.174v-175r; AHPS, Libro cabildo 4753, 23/01/1689, } \\
\text { f.209v; AHPS, Libro cabildo 4754, 12/08/1700, ff. 43r-44v; AHPS, Libro cabildo 4755(1700-1706), } \\
/ 07 / 1700 \text { f. 4v; AHPS, Libro cabildo 4755, 04/07/1703, s/f; AHPS, Libro cabildo 4766(1761-1765) } \\
06 / 12 / 1761, \text { ff. 22v-23r. }\end{array}$ \\
\hline
\end{tabular}

